\title{
A robustness analysis of the bonding process of joints in wind turbine blades
}

\author{
Spangenberg, J; Uzal, A.; Nielsen, M. W. ; Hattel, J. H.
}

Published in:

International Journal of Adhesion and Adhesives

Link to article, DOI:

10.1016/j.ijadhadh.2018.06.009

Publication date:

2018

Document Version

Peer reviewed version

Link back to DTU Orbit

Citation (APA):

Spangenberg, J., Uzal, A., Nielsen, M. W., \& Hattel, J. H. (2018). A robustness analysis of the bonding process of joints in wind turbine blades. International Journal of Adhesion and Adhesives, 85, 281-285.

https://doi.org/10.1016/j.ijadhadh.2018.06.009

\section{General rights}

Copyright and moral rights for the publications made accessible in the public portal are retained by the authors and/or other copyright owners and it is a condition of accessing publications that users recognise and abide by the legal requirements associated with these rights.

- Users may download and print one copy of any publication from the public portal for the purpose of private study or research.

- You may not further distribute the material or use it for any profit-making activity or commercial gain

- You may freely distribute the URL identifying the publication in the public portal

If you believe that this document breaches copyright please contact us providing details, and we will remove access to the work immediately and investigate your claim. 


\section{Author's Accepted Manuscript}

A robustness analysis of the bonding process of joints in wind turbine blades

J. Spangenberg, A. Uzal, M.W. Nielsen, J.H. Hattel

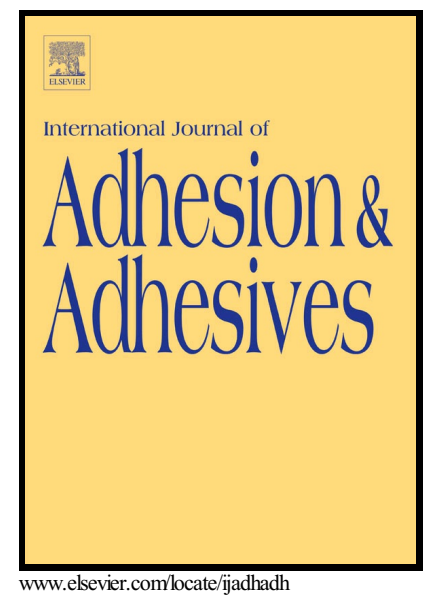

PII: $\quad$ S0143-7496(18)30164-7

DOI: $\quad$ https://doi.org/10.1016/j.ijadhadh.2018.06.009

Reference: JAAD2229

To appear in: International Journal of Adhesion and Adhesives

Received date: 11 April 2018

Accepted date: 28 May 2018

Cite this article as: J. Spangenberg, A. Uzal, M.W. Nielsen and J.H. Hattel, A robustness analysis of the bonding process of joints in wind turbine blades, International Journal of Adhesion and Adhesives, https://doi.org/10.1016/j.jjadhadh.2018.06.009

This is a PDF file of an unedited manuscript that has been accepted for publication. As a service to our customers we are providing this early version of the manuscript. The manuscript will undergo copyediting, typesetting, and review of the resulting galley proof before it is published in its final citable form. Please note that during the production process errors may be discovered which could affect the content, and all legal disclaimers that apply to the journal pertain. 


\title{
A robustness analysis of the bonding process of joints in wind turbine blades
}

\author{
J. Spangenberg ${ }^{1}$, A. Uzal ${ }^{1}$, M. W. Nielsen ${ }^{2}$, J. H. Hattel ${ }^{1}$ \\ ${ }^{1}$ Department of Mechanical Engineering, Technical University of Denmark, 2800 \\ Lyngby, Denmark \\ ${ }^{2}$ LM Wind Power, 6640 Lunderskov, Denmark
}

\begin{abstract}
In this paper, a numerical model is used to perform a robustness analysis of the bonding process of a joint between the two shells composing a wind turbine blade. The flow behaviour of the bonding adhesive is quantified on a rheometer and the Herschel-Bulkley material model is utilized to approximate the rheological data set. The material model parameters are implemented in the numerical model, which is validated by comparison with experimental results. The robustness analysis is focused on analysing the adhesive position and initial shape as well as the inclination angle's effect on the squeeze force and final adhesive geometry. The results illustrate that the numerical model can assist in increasing the strength of the joint, decreasing the risk of residual stress induced cracks, and minimizing cost/waste and mass of the blade.
\end{abstract}

Keywords: Wind turbine blades, Joints, Squeeze flow, Herschel-Bulkley material model, Numerical modelling

\section{Introduction}

In the wind industry, adhesive bonding is used as the predominant method to assemble the main parts of a wind turbine blade [1] and the bondline quality plays a crucial role on the blade's structural reliability. More specifically, the bondlines have to withstand complex stress states and harsh environmental conditions in operation and defects at these bondlines such as voids or thicknesses out of tolerance have a huge influence on the structural performance of the blade [2]. Therefore, obtaining a better understanding of how the adhesive flows and fills the gap between the components during the manufacturing process is paramount in order to improve the reliability, reduce production cycle time as well as need for repairs. Various parameters may influence the flow of the adhesive and its final quality such as inclination angle, surface roughness, surface 
temperature, adhesive shape and size, open time, and rheological properties of the adhesive itself. The deposited adhesive on the bonding surfaces has to keep its initial shape and not start curing until the actual bonding occurs. In order to obtain such characteristics, two-component thermosetting polymers are typically used [1]. The flow behaviour of these adhesives is non-Newtonian with a yield stress that insures the thermosetting polymer to keep its shape when exposed to a shear stress that is below the yield stress [1]. Such flow behaviour can be described by usage of the Herschel-Bulkley (H-B) material model [3]. In order to ensure bonding, high forces are required in blade production due to the highly viscous adhesives. The predominant interaction in a bonding process can be considered as a squeeze flow (SF) problem; two surfaces merged together by a force, with adhesive in between. In the bonding process, the upper mould approaches the lower mould, exerting a force on the adhesive, which in turn is forced to flow between two rough laminate surfaces. The SF of certain materials has been examined and used as an alternative technique to conventional rheometry for material characterization - termed SF rheometry [4-9]. In other studies, the SF forces have been analysed under different types of boundary conditions [10-12]. Recently, Bergamasco et al. [13] analysed the forces exerted by the adhesive to the substrate during SF of adhesively bonded joints. A generalized 3D analytical solution for a H-B fluid with any initial shape of the adhesive was introduced. For a wedge-shaped geometry, a numerical model was also developed and the results were compared with experiments. Similarly, Adams et al. [14] as well as Karapetsas and Tsamopoulos [15] studied the SF of nonNewtonian materials numerically and compared the obtained results with experimental data.

In this study, a numerical model is developed to emulate the bonding process of a joint between the two shells composing a wind turbine blade. The numerical model is used to perform a robustness analysis in which single parameters are varied in order to quantify process parameters - that vary along the length direction of the wind turbine blade influence on the final joint quality. The varied parameters includes the adhesive shape and positioning as well as the inclination of the blade bonding surface. The investigation as well as the paper are divided into three parts. Firstly, the rheological behavior of a polymer adhesive used for wind turbine blade bonding is characterized through cone-and- 
plate rheometry by adopting a H-B material model. Subsequently, a numerical model to simulate the SF of the adhesive between two parallel plates is developed and validated by comparison with experimental results. Finally, the model is extended in order to simulate the bonding process of non-parallel substrate surfaces with various angles, adhesivepositions and -initial shapes.

\section{Material characterization}

The material in focus was a thermosetting multi-component vinylester adhesive, based on a Bisphenolic A backbone, catalysed by a peroxide, which had a yield stress and shear thinning behaviour, see Fig. 1. Cone-and-plate rheometry was used for the rheological characterization of the polymer. Due to the very low mixing ratio and the long gelation time, the influence of the hardener on the rheological properties was neglected and hence the tests were performed with only resin material. The rheological measurements were conducted with an Anton Paar® Modular Compact Rheometer (model MCR 502). The diameter of the cone was $25 \mathrm{~mm}$ with a cone angle of $2^{\circ}$. The measurements were carried out at room temperature $\left(20^{\circ} \mathrm{C}\right)$. The sample was subjected to constant shear rate values in the interval $0.11 / \mathrm{s}$ to $100 \mathrm{1} / \mathrm{s}$. Thirty measurements were performed within the interval following a logarithmic progression. The duration of each measurement logarithmically varied between 30 seconds from the beginning to 3 seconds at the end. The samples were pre-sheared for 30 seconds at $11 /$ s prior to the tests in order to remove the air voids and homogenize the samples. The non-linear viscoplastic behaviour of the polymer was approximated with the H-B material model, i.e.

$$
\tau=\tau_{o}+K \dot{\gamma}^{n}
$$

where $\tau_{o}$ is the yield stress, $\mathrm{K}$ is the consistency and $\mathrm{n}$ is the flow index. The parameters of the H-B material model were found as: $\tau_{o}=342 \mathrm{~Pa}, \mathrm{~K}=52.88 \mathrm{~Pa} \cdot \mathrm{s}^{\mathrm{n}}$, and $\mathrm{n}=0.37$. The $\mathrm{H}-\mathrm{B}$ material model was found to approximate the rheological data fairly well with an $\mathrm{R}^{2}$ $=0.9446$, which was better than other models (e.g the Bingham material model). 


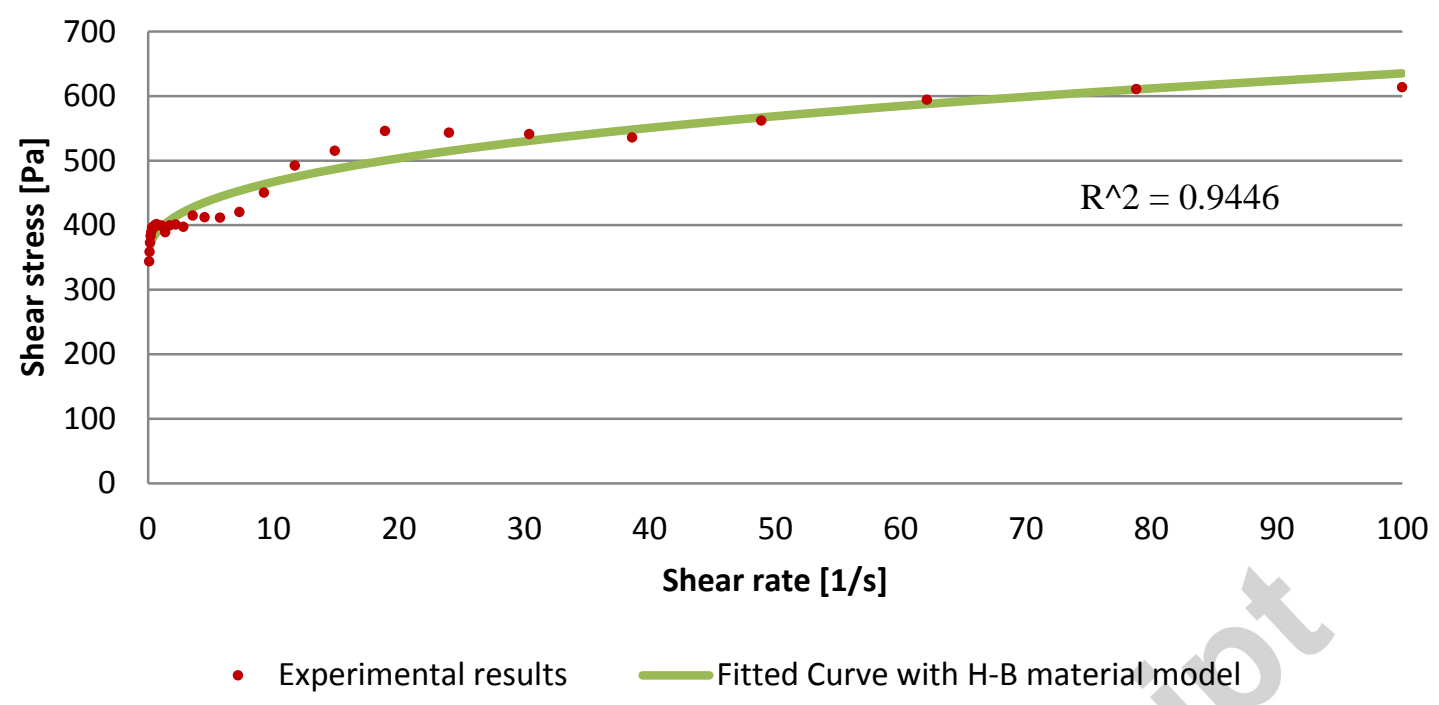

Figure 1: Cone-and-plate rheometry vs. fitted curve with H-B material model.

\section{Numerical model}

Governing Equations and Setup

The governing equations for the flow of the polymer are the continuity equation (assuming incompressibility) and momentum conservation equation:

$$
\begin{aligned}
& \nabla \cdot \boldsymbol{v}=0 \\
& \rho\left(\frac{\partial v}{\partial t}+\boldsymbol{v} \cdot \nabla \boldsymbol{v}\right)=-\nabla p+\mu \nabla^{2} \boldsymbol{v}
\end{aligned}
$$

where $\rho$ is the density, $v$ is the velocity, $p$ is the pressure and $\mu$ is the dynamic viscosity. The numerical SF model was developed in the commercial finite volume based software Flow-3D, which previously with success has been utilized to describe flow of nonNewtonian fluids by the authors [16-18]. The model tracked the free surface of the polymer by usage of the volume-of-fluid method [19], which is considered to be one of the most accurate interface tracking algorithms in a Eulerian framework [20]. The pressure and velocity fields were solved implicitly and the flow behaviour of the fluid was described by the H-B material model parameters that were derived based on the rheological measurements. The numerical model adapted the $\mathrm{H}-\mathrm{B}$ material model by calculating the apparent viscosity in each control volume at every time-step based on the calculated shear rates. The plates were modelled as rigid solids where the upper plate 
moved towards the bottom plate with a constant speed, which in the rest of the paper is referred to as the bonding speed. A no-slip boundary condition at the plate-fluid interfaces was assumed, while no gravitational effect was taken into account in the model.

\section{Validation}

In previous work by the authors, three identical SF experiments were performed with the thermosetting multi-component vinylester adhesive [21]. The experiments were carried out with two plywood plates covered by foil, see Fig. 2. The top and bottom plate had a width of 80 and $150 \mathrm{~mm}$, respectively, and the initial shape of the adhesive was a rectangular prism with a width of $25 \mathrm{~mm}$, a height of $15 \mathrm{~mm}$, and a length of $100 \mathrm{~mm}$. The plates had initially a gap of $15 \mathrm{~mm}$ and were squeezed together with a speed of 5 $\mathrm{mm} / \mathrm{s}$ until reaching a clearance of $1.3 \mathrm{~mm}$. In Fig. 3, the final geometry of the adhesive is shown for one of the experiments. In [21], the experimental results were compared with a numerical model that used the Bingham material model in order to describe the rheological behaviour of the adhesive. The plastic viscosity was adapted from the material specification, while the yield stress was estimated. The results of the experiments and numerical model were in quite good agreement. In this study, the experimental results are compared with the numerical model that approximates the rheological measurements of the adhesive with the H-B material model $\left(\tau_{o}=342 \mathrm{~Pa}, \mathrm{~K}\right.$ $=52.88 \mathrm{~Pa} \cdot \mathrm{s}^{\mathrm{n}}$, and $\mathrm{n}=0.37$ ). The simulated geometry is presented in Fig. 4, where only a quarter of the adhesive is modelled as symmetry is utilized in order to decrease the computational time. The quantitative comparison is carried out via the distances I, II, III (see Fig. 3), and IV (see Fig. 4) that corresponded to the total length, squeeze-out length, width, and height of the final geometry of the adhesive, respectively. The distances for the experiments (averaged values) and numerical model are seen in Tab 1. A good agreement between the experimental and numerical results were found, which indicated that the numerical model is trustworthy. 


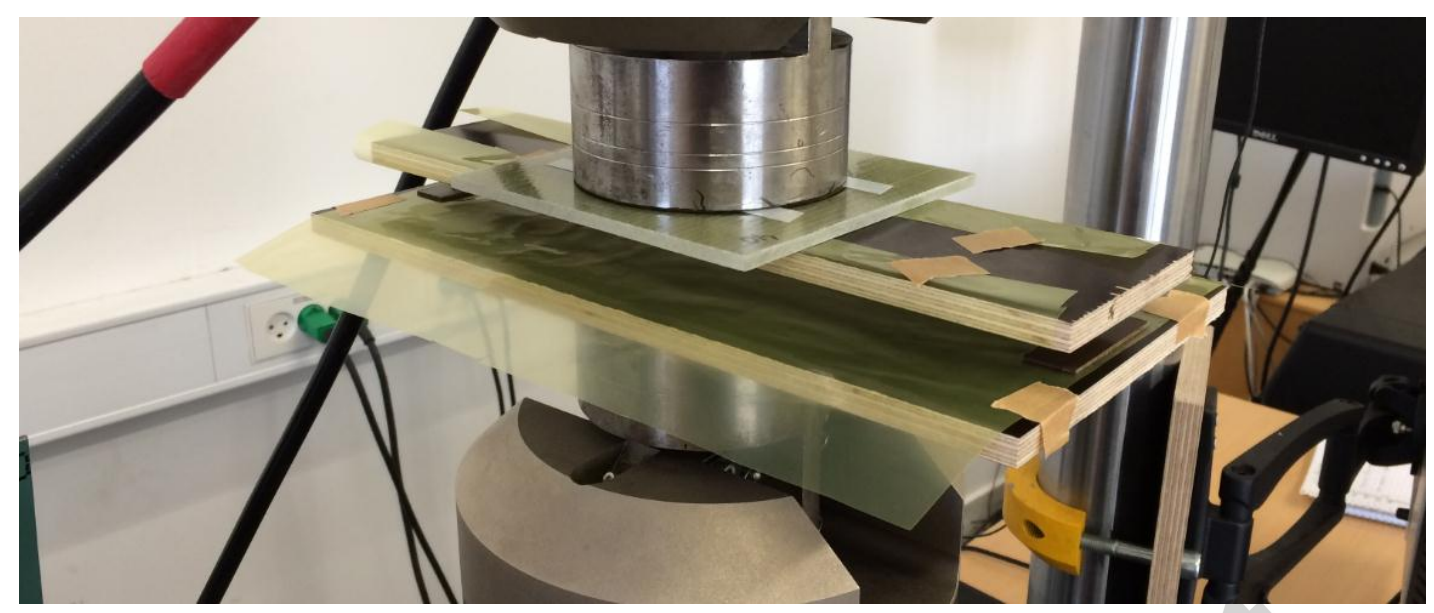

Figure 2: Test setup for the SF experiments [21].

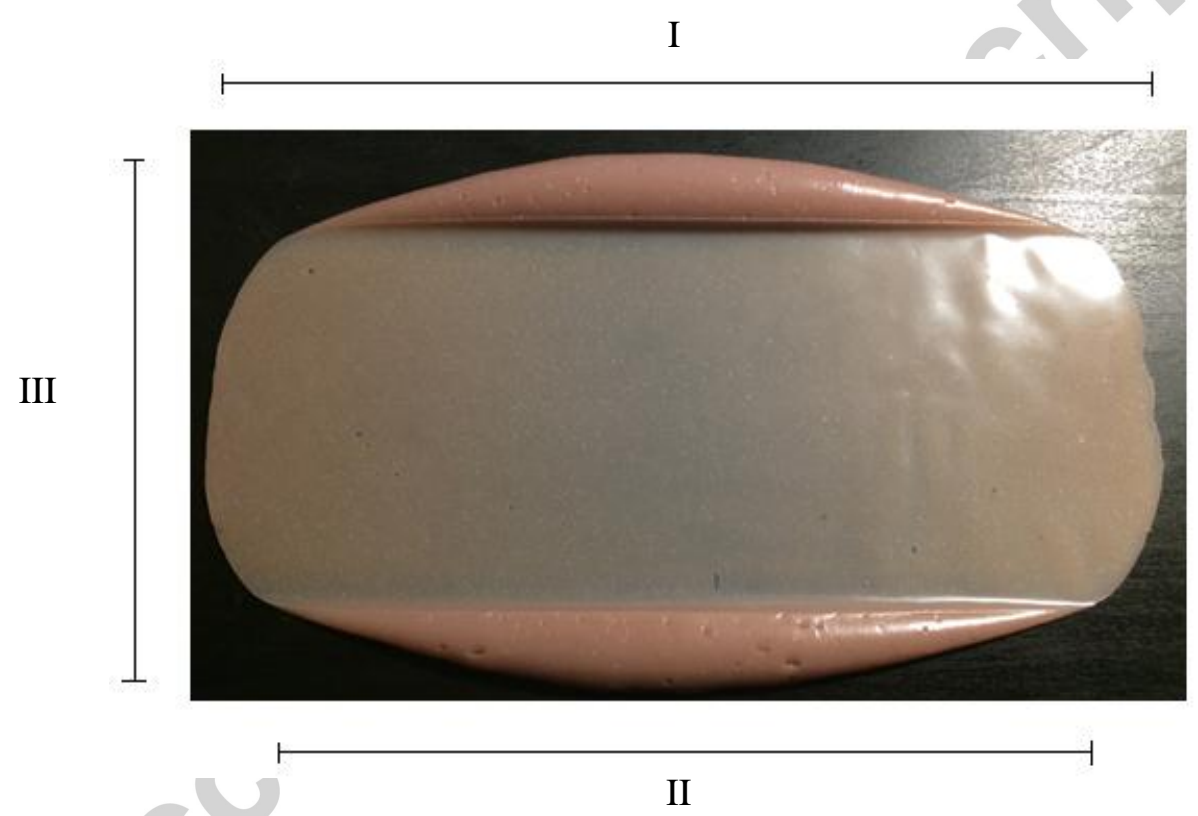

Figure 3: Final adhesive geometry after SF experiment [21]. I is the total length, II is squeeze-out length, and III is the width. 

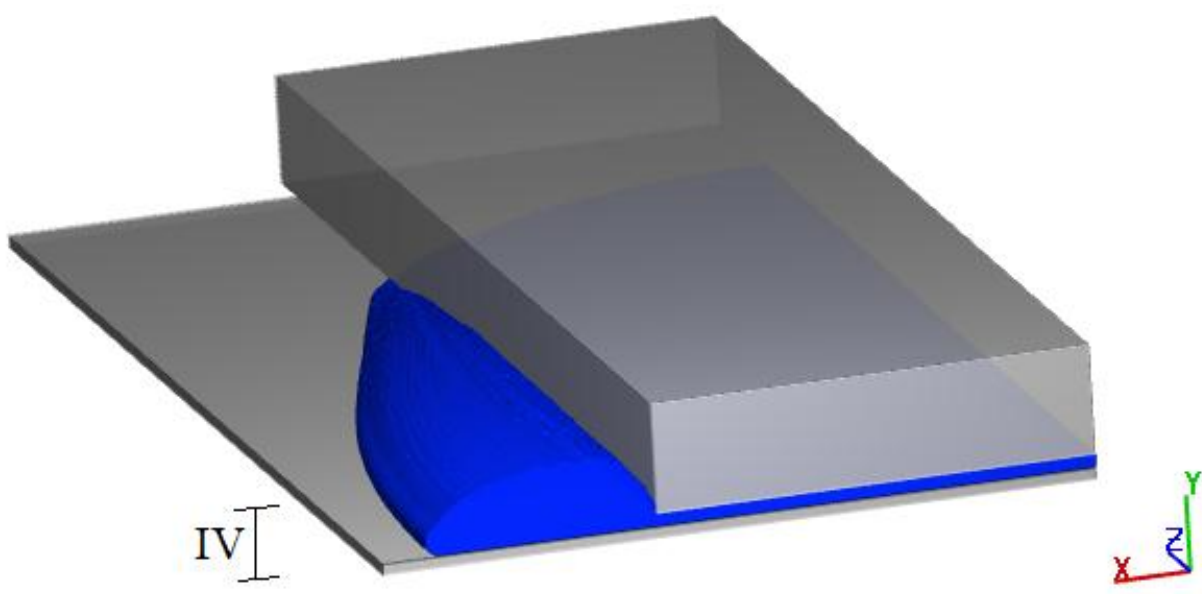

Figure 4: Final adhesive geometry simulated by the numerical model that approximates the rheological behaviour of the adhesive with the H-B material model. IV is the height of the adhesive.

Table 1: Distances for experiment (averaged values) and numerical model.

\begin{tabular}{lcc}
\hline & Experiment & Model \\
\hline Total length (I) [mm] & 202 & 204 \\
Squeeze-out Length (II) [mm] & 170 & 166 \\
Width (III) [mm] & 116 & 121 \\
Height (IV) [mm] & 7 & 7 \\
\hline
\end{tabular}

\section{Robustness analysis}

This section describes the robustness analysis for a joint between the two main shells of a wind turbine blade. The analysis is focusing on analysing the adhesive position and initial shape as well as the inclination angle's effect on the SF forces and final adhesive geometry. An illustration of the parameter variation is seen in Fig. 5. The parameter variation range is representative for a majority of the bonding line, from blade root to tip. The robustness analysis covers:

- Plate angles: $3^{\circ}, 4^{\circ}, 5^{\circ}, 6^{\circ}$, and $7^{\circ}$

- Initial shape of adhesive [width x height]: $154 \mathrm{~mm}$ x 20mm, $140 \mathrm{~mm}$ x $22 \mathrm{~mm}$, $124 \mathrm{~mm} \times 25 \mathrm{~mm}, 114 \mathrm{~mm} \times 27 \mathrm{~mm}$ and $102 \mathrm{~mm} \times 30 \mathrm{~mm}$ 
- Position of adhesive from the left edge: $35 \mathrm{~mm}, 50 \mathrm{~mm}, 65 \mathrm{~mm}, 80 \mathrm{~mm}$ and 95 $\mathrm{mm}$

In the robustness analysis, the simulations were carried out with a 2-D version of the numerical model in order to decrease the computational cost. Furthermore, a constant bonding speed of $8 \mathrm{~mm} / \mathrm{s}$ until reaching a gap of $3 \mathrm{~mm}$ was used in this analysis. The gap now refers to the gap at $x=0 \mathrm{~m}$, see Fig. 6 . The figure illustrates the final geometry of the SF simulation with the plate angle of $7^{\circ}$.

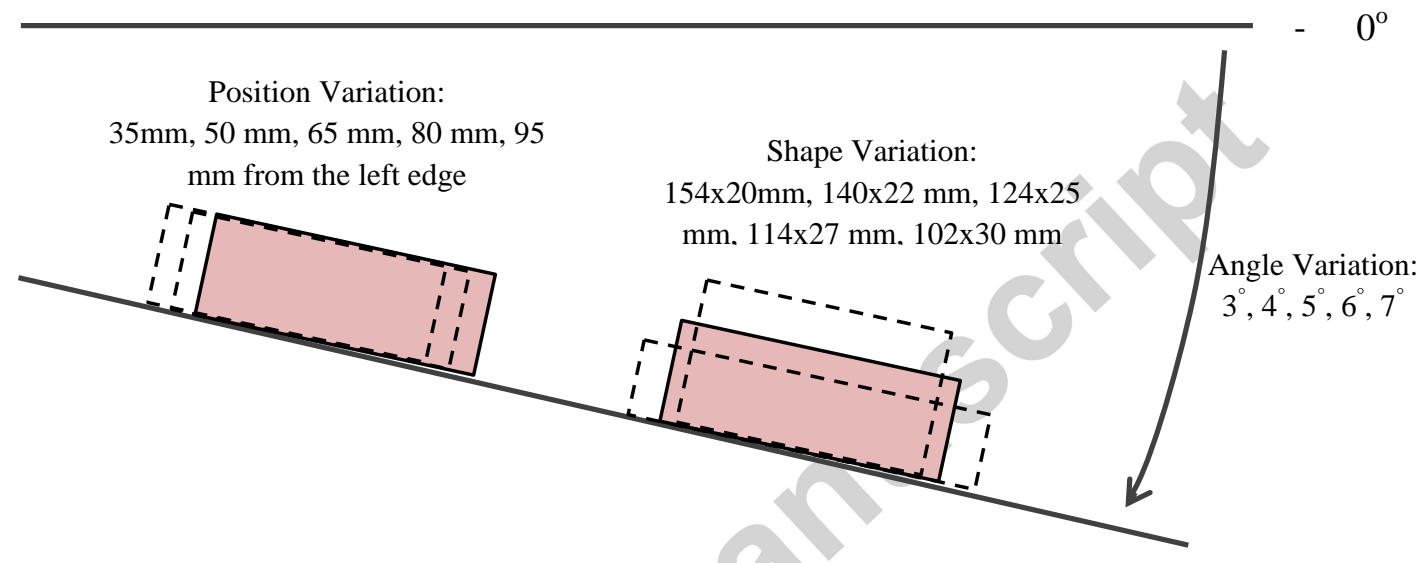

Figure 5: Illustration of the parameter variation.

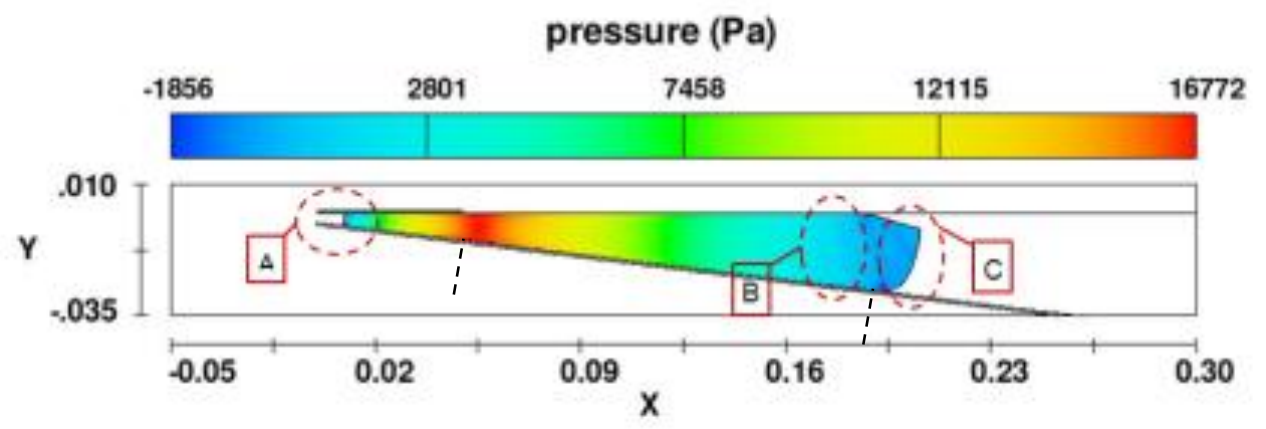

Figure 6: Final geometry of the SF simulation with the plate angle of $7^{\circ}$. The regions $\mathrm{A}$, $\mathrm{B}$, and $\mathrm{C}$ correspond to an area of the joint where no adhesive is located, an undesirable thick bondline is obtained, and non-deformed adhesive is observed, respectively. The black dotted lines show the initial left and right end of the adhesive. Note that the lengths are given in meters. 
The pressure distribution on the top plate at the final stage for various angles is illustrated in Fig. 7. In these five simulations, the initial shape of the adhesive was a width of 140 $\mathrm{mm}$ and a height of $22 \mathrm{~mm}$. In addition, the left end of the adhesive was positioned 50 $\mathrm{mm}$ from the left edge of the plates. As seen in Fig. 7, a slight angular variation leads to a considerable change in the pressure. The maximum pressure is less than half when using an angle of $7^{\circ}$ as compared to an angle of $3^{\circ}$, which thereby reduces the requirements of the equipment that is used to assemble the two main parts of a wind turbine blade. On the other hand, the final geometry of the adhesive is less reliable when increasing the angle, as illustrated in Fig. 6. In the figure, three undesired phenomena are highlighted. Region A illustrates an area of the joint where no adhesive is located that obviously decreases the strength. In region B, a thick bondline is obtained, which increases the probability of residual stress induced cracks. Finally, in region C, non-deformed adhesive is predicted, which is undesirable as it does not contribute to the strength of the joint, but rather increase the cost/waste and mass of the blade.

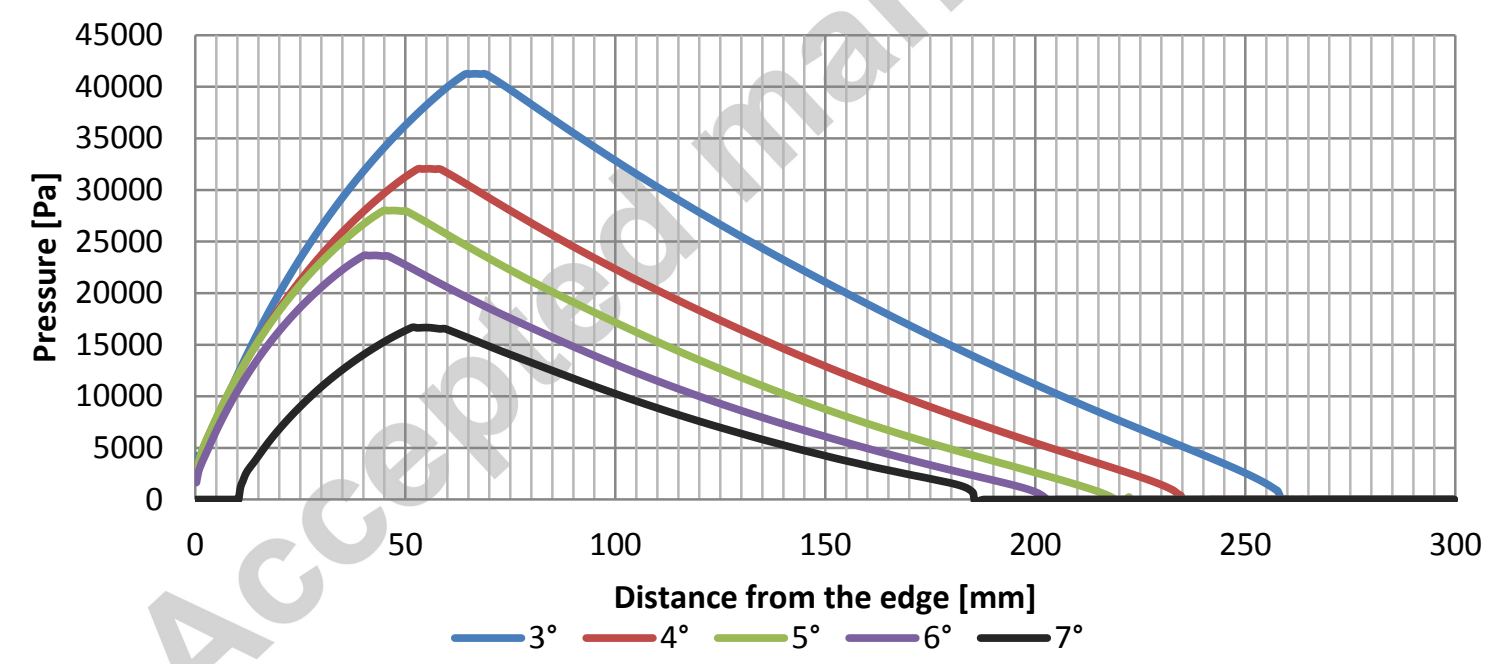

Figure 7: Pressure distribution on the top plate at the final stage for the simulations with angles varying from $3^{\circ}$ to $7^{\circ}$.

In order to evaluate the effect of the initial shape of the adhesive on the SF force and final geometry, five simulations with the width and height of [154 mm x $20 \mathrm{~mm}$ ], [140 mm x $22 \mathrm{~mm}$ ], [124 mm x $25 \mathrm{~mm}$ ], [114 mm x $27 \mathrm{~mm}$ ] and [102 mm x $30 \mathrm{~mm}$ ] were executed. The volumes of the adhesive samples were kept the same in each case. Fig. 8 illustrates the pressure distribution and final shape of the adhesive for the five cases. In these 
simulations, the centreline of the adhesive was positioned $120 \mathrm{~mm}$ from the left edge of the plates that had an angle of $5^{\circ}$. The pressure distribution in each of the simulations is approximately the same, but in the simulations having the longest width (see Fig. 8a and b), a small region with a non-derformed adhesive is obtained, thereby creating waste and unwanted mass as previously mentioned. The SF force as a function of the gap for the five simulations with different initial shape of the adhesive is seen in Fig. 9. The fastest load increase is seen for the smaller bond gaps, as they first get in contact with the upper plate, but due to the constant adhesive volume in the five cases, the final SF force ends up being almost the same. 

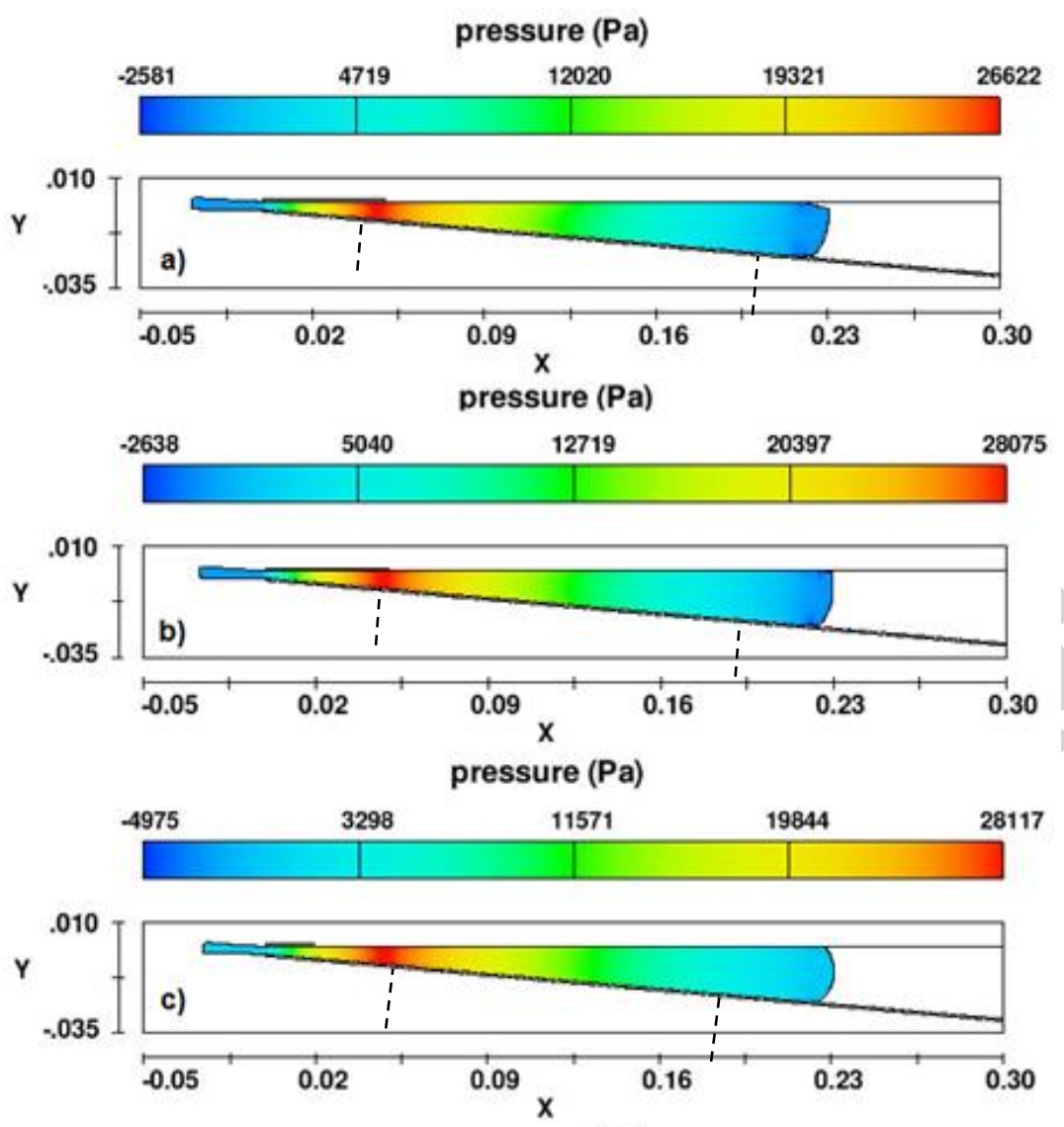

pressure (Pa)
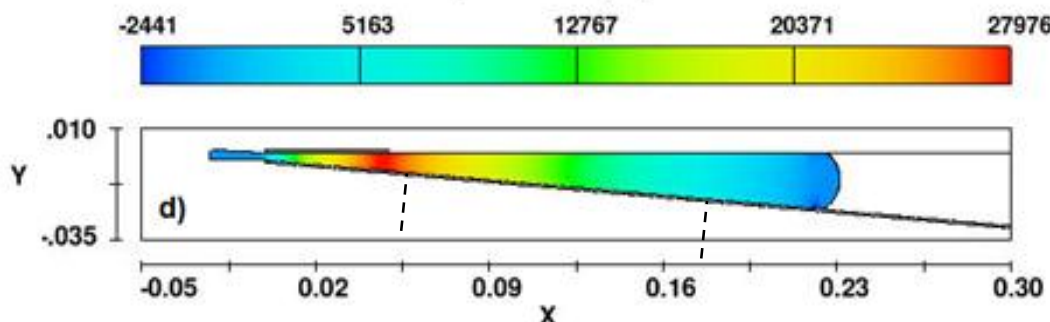

pressure $(\mathrm{Pa})$

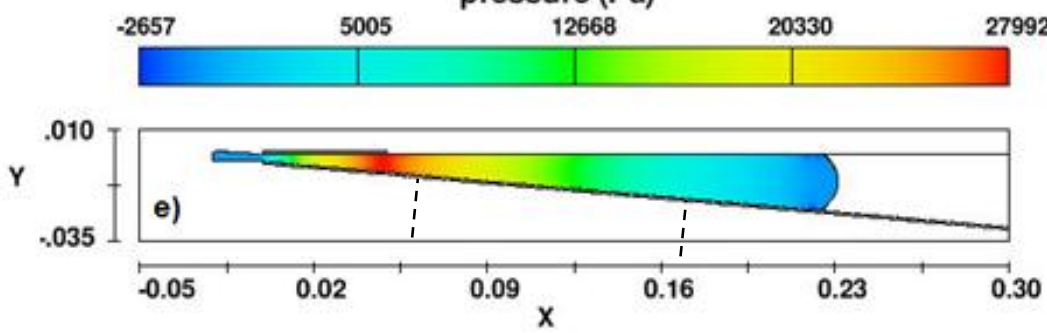

Figure 8: Pressure distribution and final adhesive geometry for the five simulations with different initial adhesive shape: a, b, c, d and e correspond to the width and height of [154 mm x $20 \mathrm{~mm}$ ], [140 mm x $22 \mathrm{~mm}$ ], [124 mm x $25 \mathrm{~mm}$ ], [114 mm x $27 \mathrm{~mm}$ ] and [102 $\mathrm{mm}$ x $30 \mathrm{~mm}$ ], respectively. The black dotted lines show the initial left and right end of the adhesive. Note that the lengths are given in meters. 


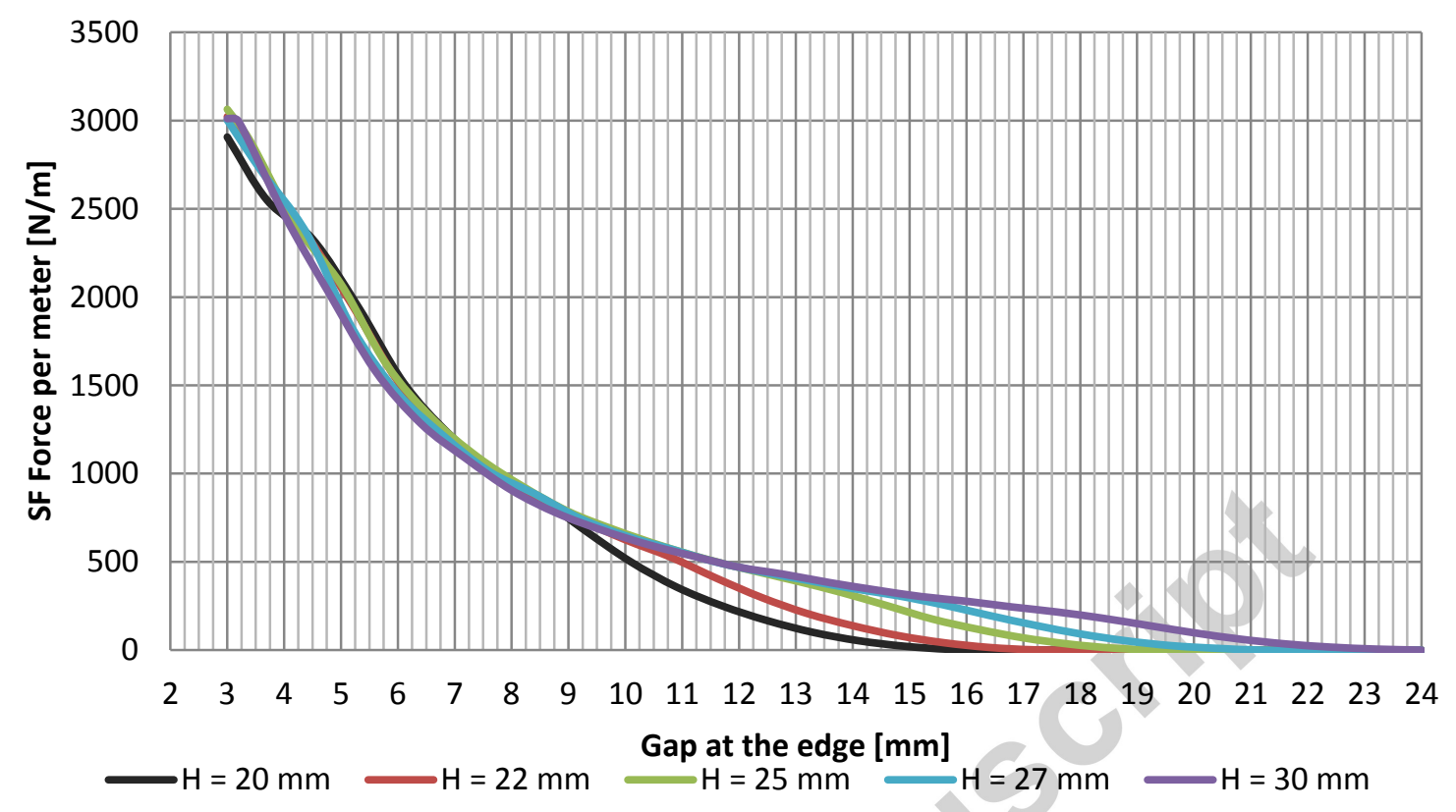

Figure 9: SF force as a function of the gap at the left edge.

Simulations with five different positions from the left edge were also analysed: $35 \mathrm{~mm}$, $50 \mathrm{~mm}, 65 \mathrm{~mm}, 80 \mathrm{~mm}$ and $95 \mathrm{~mm}$. The simulations were carried out with a width of 140 $\mathrm{mm}$, a height of $22 \mathrm{~mm}$, and a plate angle of $5^{\circ}$. Fig. 10 illustrates the pressure distribution on the top plate for each case when the gap between the plates at the edge reached $3 \mathrm{~mm}$. The further the adhesive is positioned from the left edge, the lower resulting SF force is observed. On the other hand, the figure also shows that a slight misplacement may lead to an area of the bondline where no adhesive is located (seen by no pressure increase), which may require time consuming repair work. In addition, the risk of obtaining an undesirable final geometry - both in terms of a thick bondline and a region with a non-deformed adhesive - increases when positioning the adhesive further from the left edge, see Fig. 11, where the adhesive was placed $80 \mathrm{~mm}$ from the edge. 


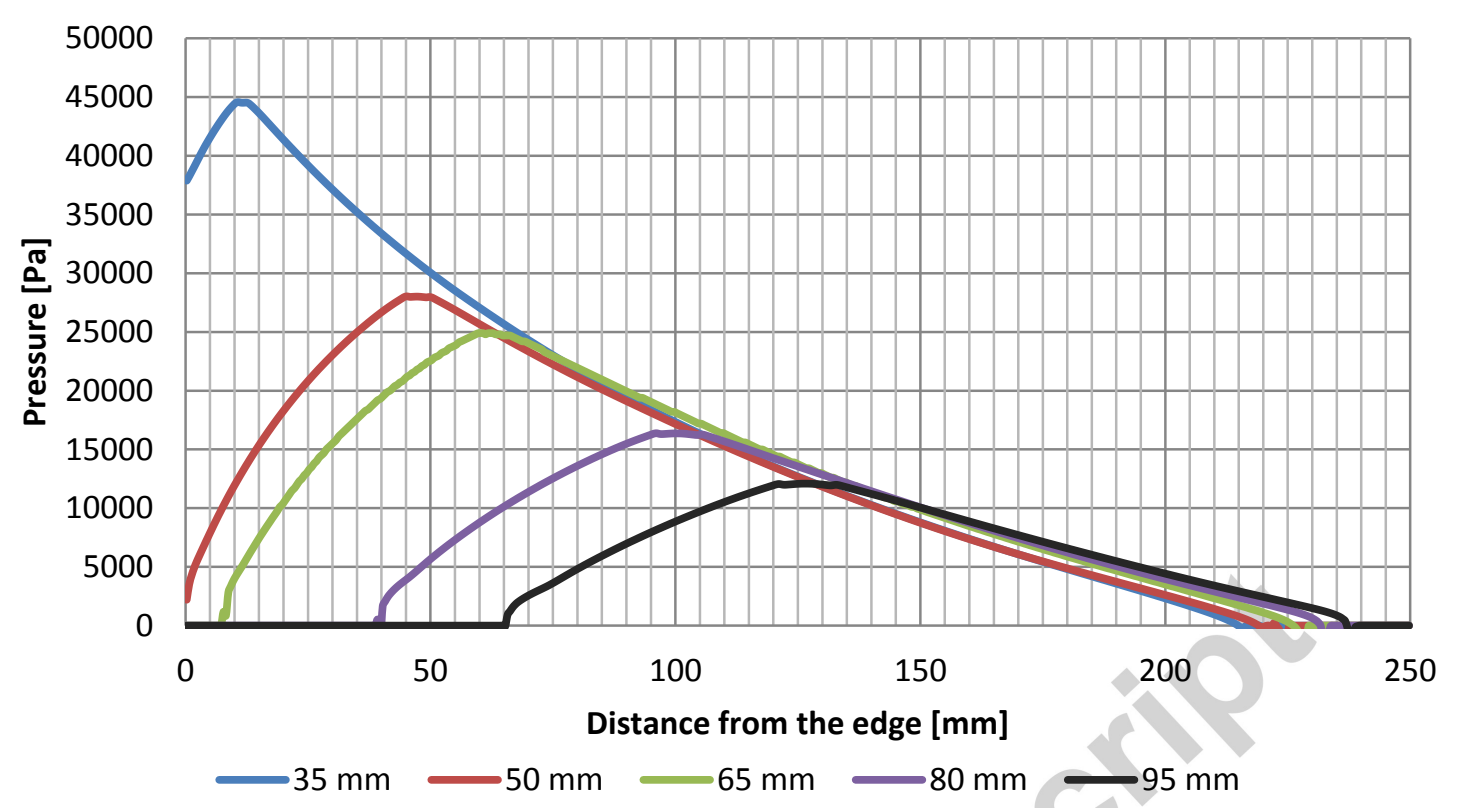

Figure 10: Pressure distribution on the top plate at the final stages for the simulations

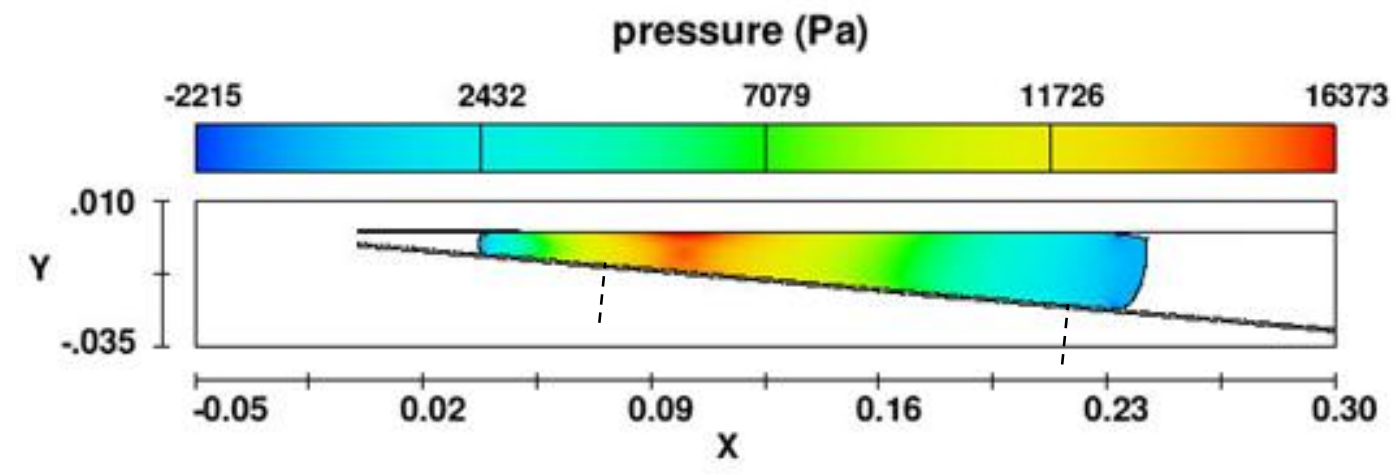

where the adhesive is placed at different distances from the left edge.

Figure 11: Pressure distribution for the simulation where the adhesive is placed $80 \mathrm{~mm}$ from the left edge. The black dotted lines show the initial left and right end of the adhesive. Note that the lengths are given in meters.

\section{Conclusion}

The adhesive polymer exhibiting a H-B flow behaviour was characterized through coneand-plate rheometry with an R-squared value of 0.94 . The rheological material model parameters were successfully implemented in the numerical model that agreed well with experimental results, when comparing the final adhesive geometry in the parallel plate SF 
setup. Subsequently, the numerical model was used to carry out a robustness analysis on non-parallel substrate surfaces with various angles, adhesive-positions and -initial shapes. It was found that with an increasing substrate angle, the maximum pressure decreased dramatically on the assembly equipment, but on the other hand, it increased the probability of obtaining undesired regions in the joint such as zones with no adhesive, thick bondlines, or non-deformed adhesive. These three regions are unwanted as they decrease the strength of the joint, increase the risk of residual stress induced cracks, and increase the cost/waste and mass of the blade, respectively. The results of the robustness analysis also illustrated that the initial adhesive geometry did not have a significant influence on the SF pressures and the final geometry, but a slight misplacement of the adhesive could result in high pressures during the bonding process or a thick bondline. In future work, the numerical model will be used to investigate potential interactions between the studied parameters.

\section{References}

[1] Subrahmanian K.P., Dubouloz F., Adhesives For Bonding Wind Turbine Blades, Reinforced Plastics 2009; 53 : 26-29.

[2] Samborsky D.D., Sears T.A., John F.M., et al., Static And Fatigue Testing Of Thick Adhesive Joints For Wind Turbine Blades, $47^{\text {th }}$ AIAA Aerospace Sciences Meeting Including The New Horizons Forum and Aerospace Exposition, Orlando, Florida 2009.

[3] Burgos G.R., Alexandrou A.N., On The Determination Of Yield Surfaces In Herschel-Bulkley Fluids, Journal Of Rheology 1999; 43 : 464-483.

[4] Rabideau B.D., Lanos C., and Coussot P., An Investigation Of Squeeze Flow As A Viable Technique For Determining The Yield Stress, Rheologica Acta 2009; 48 : 517 526.

[5] Campanella O.H., Peleg M., Squeezing Flow Viscometry For Nonelastic Semiliquid Foods - Theory And Applications, Critical Reviews In Food Science and Nutrition 2002; 42 : 241-264.

[6] Covey G.H., Use Of The Parallel-Plate Plastometer For The Characterisation Of Viscous Fluids With A Yield Stress, Journal Of Non-Newtonian Fluid Mechanics 1981; $8: 249-260$. 
[7] Meeten G.H., Squeeze Flow Of Soft Solids Between Rough Surfaces, Rheologica Acta 2004; 43 : 6-16.

[8] Meeten G.H., Constant-Force Squeeze Flow Of Soft Solids, Rheologica Acta 2002; 41 : 557-566.

[9] Engmann J., Servais C., and Burbidge A.S., Squeeze Flow Theory And Applications To Rheometry: A Review, Journal Of Non-Newtonian Fluid Mechanics 2005; 132 : 127.

[10] Sherwood J.D., Durban D., Squeeze-Flow Of A Herschel-Bulkley Fluid, Journal Of Non-Newtonian Fluid Mechanics 1998; 77 : 115-121.

[11] Meeten G.H., Flow Of Soft Solids Squeezed Between Planar And Spherical Surfaces, Rheologica Acta 2005; 44 : 563-572.

[12] Hoffner B., Campanella O.H., Corradini M.G., and Peleg M., Squeezing Flow Of A Highly Viscous Incompressivle Liquid Pressed Between Slightly Inclined Lubricated Wide Plates, Rheologica Acta 2001; 40 : 289-295.

[13] Bergamasco L., Izquierdo S., Duvivier E., Royo J.M., Chiminelli A., and Jiménez M.A., Generalized Analytical Solution For Compressive Forces In Adhesively-BondedJoint Assembling, International Journal Of Adhesion \& Adhesives 2014; 52 : 26-30.

[14] Adams M.J., Aydin I., Briscoe B.J., Sinha S.K., A Finite Element Analysis Of The Squeeze Flow Of An E1asto-Viscoplastic Paste Material, Journal Of Non-Newtonian Fluid Mechanics 1997; 71:41-57.

[15] Karapetsas G., Tsamopoulos J., Transient Squeeze Flow Of Viscoplastic Materials, Journal Of Non-Newtonian Fluid Mechanics 2006; 133 : 35-56.

[16] Spangenberg J., Roussel N., Hattel J., Stang H., Skocek J., Geiker M., Flow induced particle migration in fresh concrete: Theoretical frame, numerical simulations and experimental results on model fluids, Cement and Concrete Research 2012; 42 : 633-641. [17] Jacobsen S., Cepuritis R., Peng Y., Geiker M. R., Spangenberg J., Visualizing and simulating flow conditions in concrete form filling using pigments, Construction \& Building Materials 2013; 49 : 328-342.

[18] Roussel N., Gram A., Cremonesi M., Ferrara L., Krenzer K., Mechtcherine V., Shyshko S., Skocek J., Spangenberg J., Svec O., Thrane L., Vasilic K., Numerical 
simulations of concrete flow: A benchmark comparison, Cement and Concrete Research 2016; 79 : 265-271.

[19] Hirt C., Nichols B., Volume of fluid (VOF) method for the dynamics of free boundaries, Journal of Computational Physics 1981; 39 : 201-225.

[20] Comminal R., Spangenberg J., Hattel J., Cellwise conservative unsplit advection for the volume of fluid method, Journal of Computational Physics 2015; 283 : 582-608.

[21] Uzal A., Spangenberg J., Nielsen M. W., Sonne M. R., Hattel J. H., Numerical modelling of the bonding process for wind turbine blades: model validation, Proceedings of the $21^{\text {st }}$ International Conference on Composite Materials (ICCM21), 2017. 